\title{
Ganoderic acids suppress growth and invasive behavior of breast cancer cells by modulating AP-1 and NF- $\mathrm{kB}$ signaling
}

\author{
JIAHUA JIANG $^{1}$, BRIAN GRIEB ${ }^{1}$, ANITA THYAGARAJAN ${ }^{1}$ and DANIEL SLIVA A,2,3 $^{1,3}$ \\ ${ }^{1}$ Cancer Research Laboratory, Methodist Research Institute, Indianapolis; ${ }^{2}$ Department of Medicine, \\ ${ }^{3}$ Indiana University Simon Cancer Center, School of Medicine, Indiana University, Indianapolis, IN, USA
}

Received December 21, 2007; Accepted February 1, 2008

\begin{abstract}
Structurally related lanostane-type triterpenes, ganoderic acid A, F and $\mathrm{H}$ (GA-A, GA-F, GA-H), were identified in an oriental medicinal mushroom Ganoderma lucidum. In the present study we evaluated the effect of GA-A, GA-H and GA-F on highly invasive human breast cancer cells. We showed that GA-A and GA-H suppressed growth (cell proliferation and colony formation) and invasive behavior (adhesion, migration and invasion) of MDA-MB231 cells. Our results suggest that GA-A and GA-H mediate their biological effects through the inhibition of transcription factors $\mathrm{AP}-1$ and $\mathrm{NF}-\kappa \mathrm{B}$, resulting in the down-regulation of expression of $\mathrm{Cdk} 4$ and the suppression of secretion of $\mathrm{uPA}$, respectively. Furthermore, the activity of ganoderic acids is linked to the hydroxylation in the position 7 and 15 (GA-A) and $3(\mathrm{GA}-\mathrm{H})$ in their triterpene lanostane structure. In conclusion, hydroxylated triterpenes from G. lucidum could be promising natural agents for the therapy of invasive breast cancers.
\end{abstract}

\section{Introduction}

Breast cancer is the most common malignancy in women and is the second leading cause of cancer death in the US. Approximately 178,480 new cases of breast cancer are expected to be diagnosed in 2007 (1). Breast cancer often progresses from the nonmetastatic and therapy-responsive phenotype to the highly invasive and metastatic phenotype, which is usually resistant to standard therapeutic procedures (2). The metastatic dissemination of tumors is responsible for treatment failure, morbidity and death in cancer patients (3). Nearly one third of women with breast cancer develops metastases and finally dies from this disease (4). Thus, the inhibition of metastasis is one of the potential therapeutic

Correspondence to: Dr D. Sliva, Cancer Research Laboratory, Methodist Research Institute, 1800 N. Capitol Ave., E504, Indianapolis, IN 46202, USA

E-mail: dsliva@clarian.org

Key words: breast cancer, invasiveness, mushroom triterpenes, ganoderic acids, urokinase-type plasminogen activator, cdk4 strategies for the treatment of breast cancer patients. The invasion and metastasis of cancer comprise a complex multistep process that includes tumor cell adhesion, extracellular matrix proteolysis, migration, proliferation at a distant site of the body and stimulation of angiogenesis $(3,5)$. Urokinase-type plasminogen activator ( $\mathrm{UPA}$ ) is a serine protease that converts inactive plasminogen to active plasmin, cleaving several components of the extracellular matrix $(3,5,6)$. uPA exerts its non-proteolytic activity through its interaction with uPA receptor ( $\mathrm{UPAR}$ ), which forms a complex with integrins and controls cell adhesion and migration (5). High levels of uPA and UPAR were reported in various human malignant cancers and are associated with advanced tumors and decreased survival time $(5,6)$. Several transcription factors have been implicated in the regulation of expression of UPA and UPAR. For example, activator protein-1 (AP-1), nuclear factor- $\mathrm{kB}$ $(\mathrm{NF}-\kappa \mathrm{B})$ and ETS family transcription factor (PEA3) control uPA expression, while AP-1, NF- $\mathrm{B}$ and Sp1 control uPAR expression $(5,6)$. Besides regulating expression of $\mathrm{uPA}$ and uPAR, AP-1 and NF- $\mathrm{kB}$ also regulate the expression of other genes involved in cell cycle progression (cyclin D1), cell survival (Bcl2, Bcl-xl), inflammatory tumor growth (cyclooxygenase-2, COX2), and angiogenesis (vascular endothelial growth factor, VEGF) among others (5,7-10). Constitutive activation of AP-1 and NF- $\mathrm{KB}$ has been detected in highly invasive breast cancer cells $(11,12)$. Therefore, the activation of AP- 1 and NF- $\mathrm{KB}$ is linked to the high proliferative potential, anti-apoptosis, and invasive and metastatic behavior of cancer cells $(8,13,14)$. We recently demonstrated that constitutive activity of AP-1 and NF- $\mathrm{B}$ is associated with invasive behavior of breast cancer cells, and that inhibition of AP-1 and $\mathrm{NF}_{-} \mathrm{\kappa B}$ results in the suppression of invasiveness and growth of these cells (13-15).

The popular medicinal mushroom Ganoderma lucidum has been widely used in eastern Asia to promote health and longevity. The dried powder of G. lucidum has been used in traditional Chinese medicine (TCM) for more than 2000 years to prevent or treat different diseases, including cancer (16). The anticancer properties of G. lucidum have been attributed to either the isolated polysaccharides, which are responsible for the stimulation of the immune system, or triterpenes, which demonstrate cytotoxic activity against a variety of cancer cells including breast, prostate, lung, colon, sarcoma, hepatoma and leukemia cells $(17,18)$. However, the identification and characterization of the most biologically active 
agents from $G$. lucidum proved to be difficult due to the complexity of G. lucidum. Recently, purified lanostanoid triterpenes isolated from G. lucidum, ganoderic acid X and ganoderic acid $\mathrm{T}$ induced apoptosis in human hepatoma and lung cancer cells, respectively $(19,20)$, suggesting that the basic lanostane structure is necessary for the biological activity of purified triterpenes. Nevertheless, the relationship between the structure and function of G. lucidum triterpenes remains to be determined.

We previously demonstrated that G. lucidum inhibits invasiveness of breast cancer cells through the suppression of $\mathrm{NF}-\kappa \mathrm{B}$, resulting in the down-regulation of the expression of UPA and its receptor (uPAR) (13). We also found that G. lucidum inhibits the growth of breast cancer cells through cell cycle arrest at $G_{0} / G_{1}$, which was mediated by the suppression of NF- $\mathrm{NB}$ signaling and the down-regulation of the expression of cyclin D1 (21). Our recent analysis by LCMS demonstrated that extracts of G. lucidum contain ganoderic acid A, F and H (GA-A, GA-F, GA-H) (Fig. 1) (15). In the present study, we compared the anti-proliferative and anti-invasive activity of three purified triterpenes isolated from G. lucidum (GA-A, GA-F, GA-H), and demonstrated that the hydroxylation of the ganoderic acids affects their biological activity.

\section{Materials and methods}

Materials. Purified ganoderic acid A (79.12\%), F (89.96\%) and $\mathrm{H}(82.31 \%)$ were purchased from ChromaDex Inc. (Santa Ana, CA). Methanol was purchased from Sigma (St. Louis, MO). GA-A, GA-F and GA-H were dissolved in methanol at a concentration of $50 \mathrm{mM}$ and stored at $4^{\circ} \mathrm{C}$. Dulbecco's phosphate-buffered saline (DPBS) was purchased from Cambrex Bio Science Walkersville, Inc. (Walkersville, $\mathrm{MD)}$.

Cell culture. The human breast cancer cell line (MDA-MB231) was obtained from ATCC (Manassas, VA). MDA-MB231 cells were maintained in Dulbecco's modified Eagle's medium (DMEM) containing penicillin $(50 \mathrm{U} / \mathrm{ml})$, streptomycin $(50 \mathrm{U} / \mathrm{ml})$ and $10 \%$ fetal bovine serum (FBS). Media, supplements and FBS were from Invitrogen (Grand Island, NY).

Cell proliferation assay. Cell proliferation was determined by the tetrazolium salt method (MTT method), according to the manufacturer's instructions (Promega, Madison, WI). Briefly, MDA-MB-231 cells $\left(2.5 \times 10^{3} /\right.$ well $)$ were cultured in a 96-well plate and treated with GA-A, GA-F and GA-H $(0.10,0.25,0.50 \mathrm{mM})$ for 24,48 and $72 \mathrm{~h}$. At the end of the incubation period, the cells were harvested, and absorption was determined with an ELISA plate reader at $570 \mathrm{~nm}$. Data points represent the mean $\pm \mathrm{SD}$ in one experiment repeated at least twice.

Colony formation (anchorage-independent growth). MDAMB-231 cells were harvested and seeded in 6-well plates coated with $1 \%$ agarose. Colony formation was assessed after incubation for 14 days in culture media with GA-A, GA-F and GA-H $(0.10,0.25,0.50 \mathrm{mM})$, which was replaced every
4 days. Plates were stained with $0.005 \%$ Crystal Violet, and the colonies were counted manually under a microscope and photographed.

Cell adhesion assay. Cell adhesion of MDA-MB-231 cells was performed with Cytomatrix Adhesion Strips coated with human vitronectin (Chemicon International, Temecula, CA), according to the manufacturer's instructions. Briefly, MDAMB-231 cells were treated with GA-A, GA-F and GA-H $(0.10,0.25,0.50 \mathrm{mM})$ for $24 \mathrm{~h}$, harvested, and counted. Cells $\left(10^{5}\right)$ were applied to the rehydrated vitronectin strips in a 96 -well plate and incubated for $1.5 \mathrm{~h}$ at $37^{\circ} \mathrm{C}$. The cells were stained with $0.2 \%$ Crystal Violet, washed, and the absorbance was determined at $570 \mathrm{~nm}$ with a microplate reader, as previously described (22). Data points represent the mean $\pm \mathrm{SD}$ in one experiment repeated at least twice.

Cell migration assay. MDA-MB-231 cells were harvested and incubated with GA-A, GA-F and GA-H $(0.10,0.25,0.50 \mathrm{mM})$ for $5 \mathrm{~h}$. Chemokinesis was assessed in Transwell chambers (6.5 mm-diameter polycarbonate filters; $8 \mu \mathrm{m}$ pore size) in the DMEM medium containing $10 \%$ FBS, as previously described $(13,22)$. After fixing and staining, the number of migrating cells was determined microscopically by enumeration at 40x magnification from at least four random fields. Data points represent the mean \pm SD of three individual filters within one representative experiment repeated at least twice.

Cell invasion assay. MDA-MB-231 cells were harvested and treated with GA-A, GA-F and GA-H $(0.10,0.25,0.50 \mathrm{mM})$ for $24 \mathrm{~h}$. Invasion was assessed in Transwell chambers $(6.5 \mathrm{~mm}$ diameter polycarbonate filters; $8 \mu \mathrm{m}$ pore size) coated with $100 \mu 1$ of Matrigel ${ }^{\mathrm{TM}}$ (BD Biosciences, Bedford, MA) diluted 1:3 with DMEM. After $24 \mathrm{~h}$ of incubation, the cells, which invaded through Matrigel were stained with hematoxylin, and their number was determined microscopically by enumeration at 40x magnification from at least four random fields. Data points represent the mean \pm SD in one experiment repeated at least twice.

UPA secretion. DMEM media from MDA-MB-231 cells treated with GA-A, GA-F and GA-H $(0.10,0.25,0.50 \mathrm{mM})$ for $24 \mathrm{~h}$ were collected and concentrated 10 -fold by a Micron YM-10 filter (Amicon, Cambridge, MA). Secretion of uPA was detected by Western blot analysis of conditioned media with anti-uPA antibody (Oncogenes Research Products, Cambridge, MA), as described (13).

Immunocytochemical staining. MDA-MB-231 cells were cultured in multichamber slides (Nunc Inc., Naperville, IL) and treated with GA-A, GA-F and GA-H $(0.10,0.25,0.50 \mathrm{mM})$ for $24 \mathrm{~h}$. After $24 \mathrm{~h}$, cells were fixed and then processed for immunocytochemical staining as described (23). Briefly, cells were incubated with prediluted blocking serum (DPBS containing $1.5 \%$ normal horse serum) for $1 \mathrm{~h}$ at room temperature, incubated with a rabbit anti-uPAR polyclonal antibody (Santa Cruz Biotechnology, Santa Cruz, CA) for $30 \mathrm{~min}$ at room temperature, and then incubated in the presence of a prediluted biotinylated anti-rabbit secondary antibody (Santa Cruz Biotechnology) for $30 \mathrm{~min}$ at room 


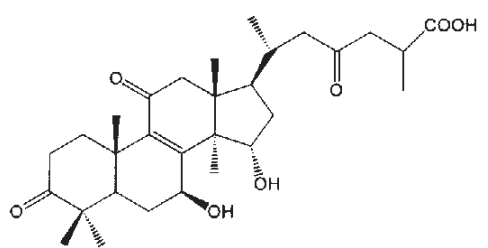

Ganoderic acid A

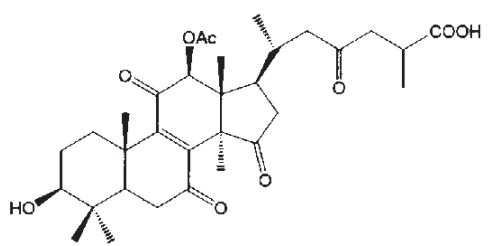

Ganoderic acid F

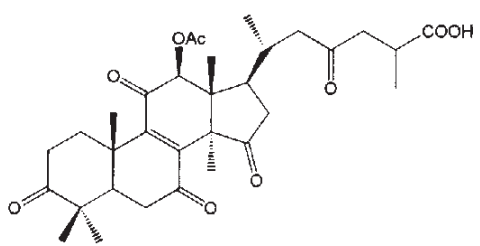

Ganoderic acid H

Figure 1. Structure of ganoderic acids.

temperature. Slides were incubated with $\mathrm{AB}$ enzyme reagent for $30 \mathrm{~min}$ and then incubated with peroxidase substrate solution (ABC staining system, Santa Cruz Biotechnology) until the desired stain intensity developed. Each step in the staining procedure was followed by three $5 \mathrm{~min}$ washes in PBS.

DNA transfection and luciferase assay. MDA-MB-231 cells $\left(2.5 \times 10^{5} /\right.$ well) were seeded into 6-well plates in DMEM with $10 \%$ FBS prior to transfection. Transient transfections were performed with the Effectene reagent (Qiagen, Valencia, CA) according to the manufacturer's instructions. Briefly, the cells were transfected with AP-1-luc or NF-кB-luc (BD Biosciences Clontech, Palo Alto, CA) reporter constructs $(1 \mu \mathrm{g})$ and $\mathrm{B}$ galactosidase expression vector pCH110 (1 $\mu \mathrm{g})$. Twenty hours after transfection, cells were washed once with DPBS, and the medium was replaced with DMEM with $10 \%$ FBS and incubated for $24 \mathrm{~h}$. After a 24-h incubation, medium was replaced with DMEM containing no FBS, and cells were treated with GA-A, GA-F and GA-H $(0.10,0.25,0.50 \mathrm{mM})$ for $24 \mathrm{~h}$. B-glactosidase activity was measured in cell lysates, as previously described (24). Normalized amounts (equal numbers of $\beta$-galactosidase units) of cell extracts were used in the luciferase assay using Lmax luminometer (Molecular Devices, Sunnyvale, CA). Data points represent the mean \pm $\mathrm{SD}$ of three independent transfection experiments.

Preparation of nuclear and whole cell extract. MDA-MB231 cells $\left(1 \times 10^{7}\right)$ were treated with GA-A, GA-F and GA-H $(0.10,0.25,0.50 \mathrm{mM})$ for $24 \mathrm{~h}$. Nuclear and whole cell extracts isolated from cells were prepared as previously described (24). The concentration of nuclear and total protein was determined according to the manufacturer's protocol (Bio-Rad Laboratories, Hercules, CA).

Western blot analysis. Equal amounts of proteins (20 $\mu \mathrm{g} / \mathrm{lane})$ were separated on 4-12\% SDS-PAGE (Invitrogen, Carlsbad, CA) and transferred to a PVDF membrane (Millipore, Bedford, MA). The membrane was incubated with the corresponding primary antibodies diluted 1:1000 in blocking solution, as follows: a rabbit anti-Cdk4 polyclonal antibody and a mouse anti- $\alpha$-tubulin monoclonal antibody (Santa Cruz Biotechnology). Anti-mouse or anti-rabbit secondary antibodies (Amersham Biosciences, Buckinghamshire, UK) were used to detect and visualize by the ECL Western Blotting Detection system (Amersham Biosciences).
Electrophoretic mobility shift assay (EMSA). Oligonucleotide probes containing consensus sequences for AP-1 and NF- $\mathrm{KB}$ binding sites were purchased from Promega, respectively. EMSA for AP-1 and NF- $\mathrm{KB}$ was performed as previously described $(14,24)$. Briefly, $1 \mu 1(40,000 \mathrm{cpm})$ of ${ }^{32} \mathrm{P}$-labeled AP-1 or NF- $\mathrm{KB}$ probe was added to the reaction mixture and incubated for another $20 \mathrm{~min}$ at room temperature. The reaction mixture was then separated on a $4.5 \%$ polyacrylamide gel running in $0.25 \mathrm{X}$ Tris/borate/EDTA (TBE) buffer. The specificity was confirmed with cold AP-1 or NF- $\mathrm{KB}$ and nonspecific $\beta-G a l$ oligonucleotides, and supershift analysis

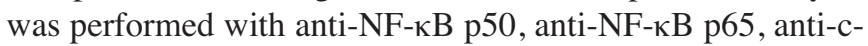
Jun, and anti-c-Fos antibody or nonspecific antibody ( $\operatorname{IgG})$, respectively.

Statistical analysis. Data are expressed as the mean \pm SD of three experiments. Minitab statistical software for Windows (Minitab Inc., State College, PA) was used for statistical analysis. Statistical differences between means were evaluated using a one-way analysis of variance (ANOVA) followed by Tukey's pairwise comparisons. $\mathrm{p}<0.05$ was considered significant.

\section{Results}

Effect of GA-A, GA-F and GA-H on the proliferation of highly invasive breast cancer cells. Even with progress in the early diagnosis and therapy, some breast cancers demonstrate highly invasive characteristics that are usually refractory to medical therapy. Therefore, we evaluated structurally related ganoderic acids (GA-A, GA-F and GA-H; Fig. 1) on highly invasive breast cancer cells. MDA-MB-231 cells were treated with increasing concentrations of GA-A, GA-F and GA-H $(0.10,0.25$ and $0.50 \mathrm{mM})$ for 24,48 and $72 \mathrm{~h}$, and proliferation was determined. As seen in Fig. 2, GA-A and GA-H significantly inhibited the growth of MDA-MB-231 cells. The growth of MDA-MB-231 cells treated with GA-A $(0.50 \mathrm{mM})$ for 24,48 and $72 \mathrm{~h}$ was inhibited by $41.7,55.1$ and $55.8 \%$, respectively (Fig. 2A). Similarly, GA-H inhibited the growth of MDA-MB-231 cells by 38.3, 48.3 and $57.7 \%$, respectively (Fig. 2C). However, the same concentrations of GA-F had no effect on the growth of MDA-MB-231 cells (Fig. 2B).

Effect of GA-A, GA-F and GA-H on the anchorageindependent growth of highly invasive breast cancer cells. 

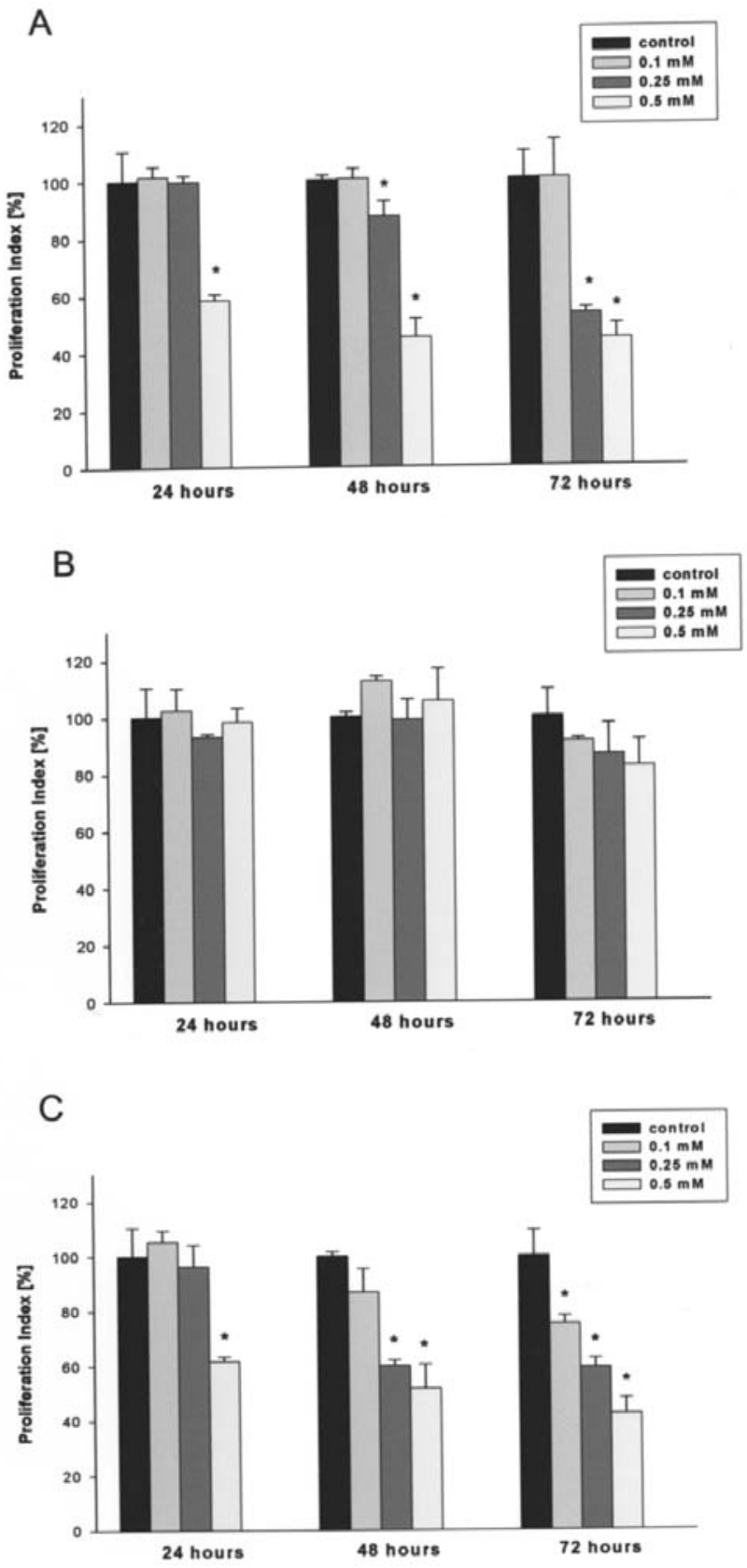

Figure 2. Effect of ganoderic acids on the proliferation of MDA-MB-231 cells. MDA-MB-231 cells were treated with (A) GA-A (0-0.5 mM), (B) GA-F $(0-0.5 \mathrm{mM})$ and $(\mathrm{C}) \mathrm{GA}-\mathrm{H}(0-0.5 \mathrm{mM})$. Cell proliferation was determined by the tetrazolium salt method. Data are the means \pm SD of triplicate determinations. Similar results were obtained in at least two additional experiments; ${ }^{*} \mathrm{p}<0.05$.

The hallmark property of cancer cells, in vitro, is that they are capable of anchorage-independent growth. Cancer cells can survive growth under a nonadhesive or anchorageindependent condition (colony formation), and colony formation is correlated with the in vivo oncogenic potential of cancer cells. Therefore, colony formation is a key parameter for cells to acquire a metastatic potential (25). In order to evaluate the effects of ganoderic acids on colony formation of highly invasive breast cancer cells, MDA-MB-231 cells were plated on agarose and incubated for 14 days with culture media containing GA-A, GA-F and GA-H $(0.10,0.25$, $0.50 \mathrm{mM})$. As seen in Fig. 3, GA-A and GA-H decreased the

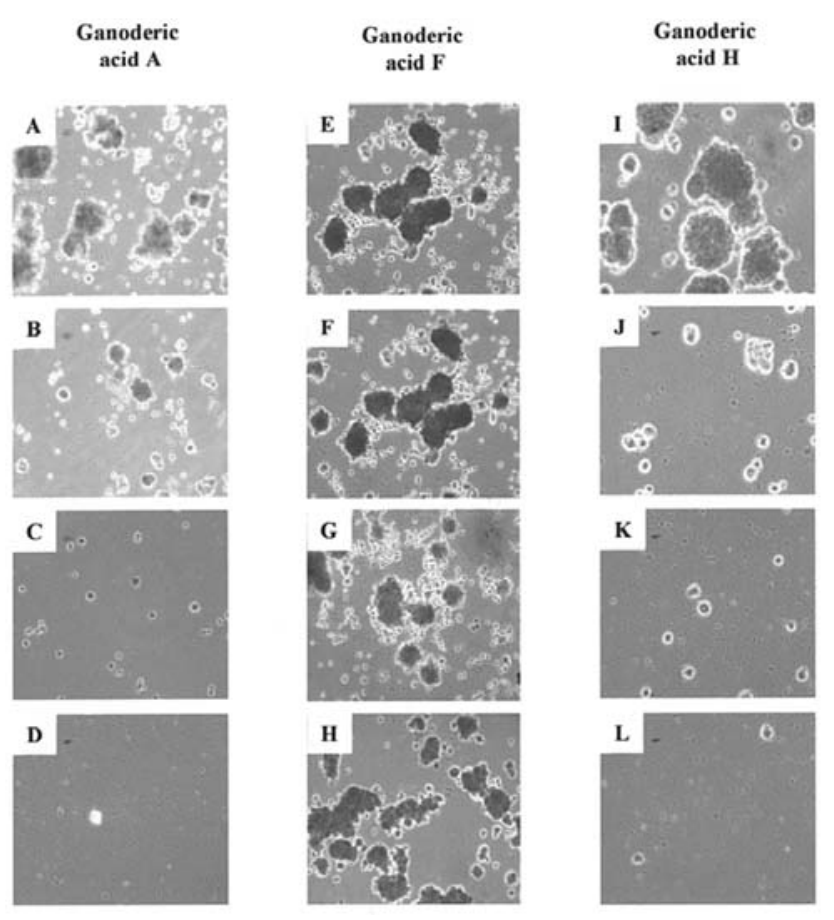

Figure 3. Effect of ganoderic acids on colony formation of MDA-MB-231 cells. Anchorage-independent growth (colony formation) of MDA-MB-231 cells was assessed on $1 \%$ agarose after incubation for 14 days with culture media containing GA-A: (A) control, (B) $0.1 \mathrm{mM}$, (C) $0.25 \mathrm{mM}$, (D) $0.5 \mathrm{mM}$; and containing GA-F: (E) control, (F) $0.1 \mathrm{mM}$, (G) $0.25 \mathrm{mM}$, (H) $0.5 \mathrm{mM}$; and containing GA-H: (I) control, (J) $0.1 \mathrm{mM}$, (K) $0.25 \mathrm{mM}$ and (L) $0.5 \mathrm{mM}$.

number of colonies of MDA-MB-231 cells in a dosedependent manner (Fig. 3A-D and I-L). However, GA-F had no effect on the amount of breast cancer cell colonies (Fig. 3E-H). These results suggest that GA-A and GA-H inhibited the anchorage-dependent (cell proliferation) as well as anchorage-independent (colony formation) growth of invasive breast cancer cells.

Effect of GA-A, GA-F and GA-H on invasive behavior of breast cancer cells. Adhesion of cancer cells to extracellular matrix or endothelial cells plays a key role in the process of metastasis. We previously demonstrated that an extract from G. lucidum inhibited the invasive behavior (adhesion, migration and invasion) of highly invasive human breast cancer cells (26). Therefore, we evaluated whether GA-A, GA-F and GA-H also inhibit the adhesion of MDA-MB-231 cells. As expected, GA-A and GA-H inhibited the adhesion of MDA-MB-231 cells, whereas GA-F did not show any effect (Fig. 4A). We found that GA-A reduced the adhesion of MDA-MB-231 cells to $71.1,51.9$ and $35.9 \%$ of the control at $0.10,0.25$ and $0.50 \mathrm{mM}$, respectively. Similarly, GA-H decreased the adhesion to $70.8,57.9$ and $43.9 \%$ of the control at $0.10,0.25$ and $0.50 \mathrm{mM}$, respectively. These results demonstrated that the inhibitory effects of GA-A and GA-H on the adhesion of MDA-MB-231 cells are dose-dependent.

The effect of GA-A, GA-F and GA-H on the motility of MDA-MB-231 cells was assessed by cell migration assay. Treatment of MDA-MB-231 cells with GA-A and GA-H demonstrated a significantly lower migration rate compared to the control (Fig. 4B). GA-A reduced the migration rate of 
A

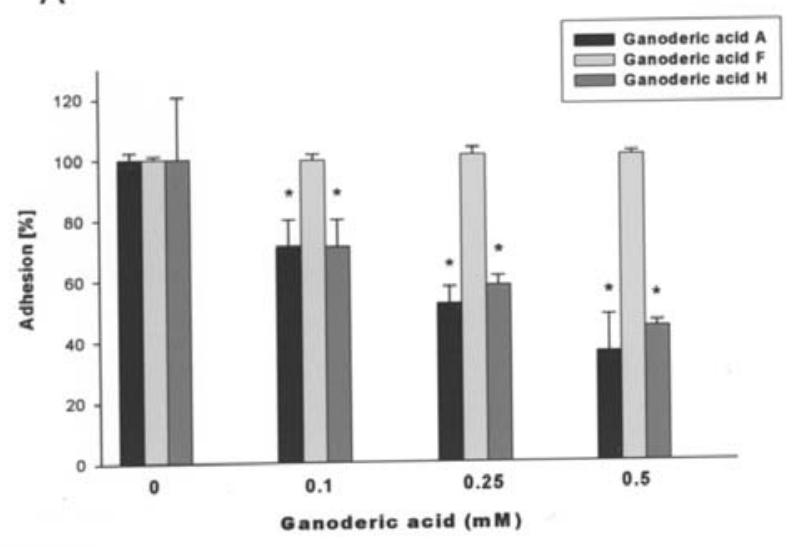

B

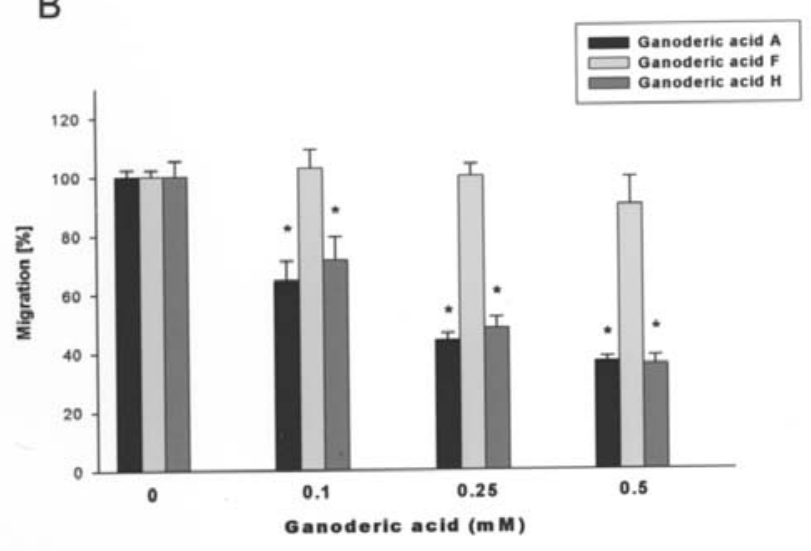

C

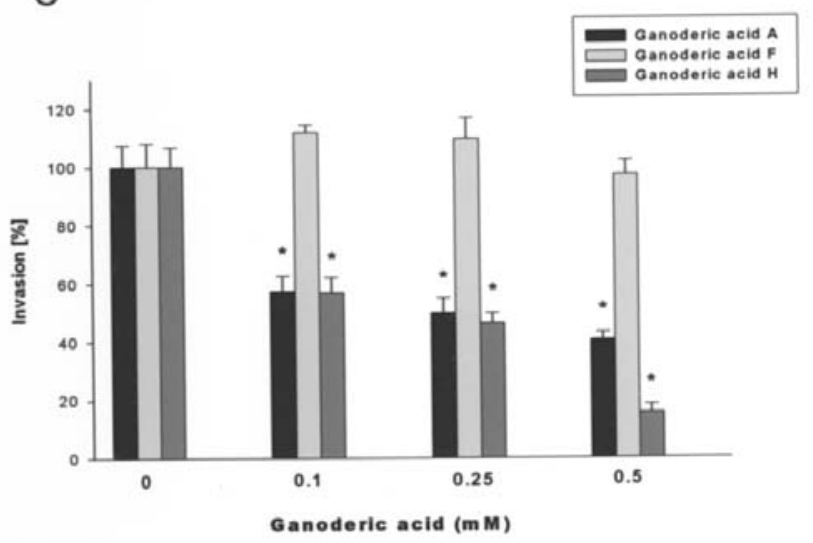

Figure 4. Effect of ganoderic acids on the invasive behavior of MDA-MB231 cells. (A) Cell adhesion. MDA-MB-231 cells were treated with GA-A, GA-F or GA-H (0-0.5 mM) for $24 \mathrm{~h}$, and cell adhesion to vitronectin was determined as described in Materials and methods. Each bar represents the mean \pm SD of three experiments; " $\mathrm{p}<0.05$. (B) Cell migration. Cell migration was determined after $5 \mathrm{~h}$ of incubation in the presence of GA-A, GA-F or GA-H (0-0.5 mM) in Boyden chambers as described in Materials and methods. Each bar represents the mean \pm SD of three experiments; ${ }^{*} \mathrm{p}<0.05$. (C) Cell invasion. Cell invasion was determined after $24 \mathrm{~h}$ of incubation in the presence of GA-A, GA-F or GA-H (0-0.5 mM) in Boyden chambers coated with Matrigel as described in Materials and methods. Each bar represents the mean $\pm \mathrm{SD}$ of three experiments; ${ }^{\mathrm{p}} \mathrm{p}<0.05$.

MDA-MB-231 cells to $64.5,44.0$ and $36.6 \%$ of the control at $0.10,0.25$ and $0.50 \mathrm{mM}$, respectively. Similarly, GA-H decreased the migration rate to $71.3,48.1$ and $35.6 \%$ of the control at $0.10,0.25$ and $0.50 \mathrm{mM}$, respectively. In contrast,
GA-F at the same time point had no effect on the migration rate of MDA-MB-231 cells (Fig. 4B).

Next we examined whether GA-A, GA-F and GA-H also modulates the invasion of MDA-MB-231 cells, because invasion is another key factor for cancer expansion and metastasis. Consistent with anchorage-independent growth, adhesion and migration, GA-A and GA-H significantly inhibited the invasion of the MDA-MB-231 cells, whereas GA-F did not show any effect on cell invasion (Fig. 4C). GA-A reduced the invasion of MDA-MB-231 cells to 57.3, 49.9 and $40.4 \%$ of the control at $0.10,0.25$ and $0.50 \mathrm{mM}$, respectively. GA-H resulted in a similar reduction in the invasion rate to $56.9,46.3$ and $15.5 \%$ of the control at 0.10 , 0.25 and $0.50 \mathrm{mM}$, respectively. These data indicate that the inhibitory effects of GA-A and GA-H on the invasion of MDA-MB-231 cells are dose-dependent.

Effect of GA-A, GA-F and GA-H on the constitutive activation of $A P-1$ and $N F-\kappa B$ in MDA-MB-231 cells. AP-1 and NF- $\mathrm{BB}$ are transcriptional activators implicated in promoting the invasive and metastatic potential of cancer cells. We previously demonstrated that G. lucidum decreased constitutive activation of AP-1 and NF- $\mathrm{KB}$ (13), and inhibited adhesion, migration and invasion of MDA-MB-231 cells $(13,26)$. The ability of GA-A and GA-H to decrease the invasive behavior of MDA-MB-231 cells suggests that ganoderic acids may affect AP-1 or NF- $\mathrm{KB}$ signaling pathways responsible for the growth and metastatic behavior of breast cancer cells. In order to determine the effect of GA-A, GA-F and $\mathrm{GA}-\mathrm{H}$ on the constitutive activation of AP-1 and NF-кB, MDA-MB-231 cells were transfected with reporter gene constructs AP-1 and NF- $\mathrm{KB}-\mathrm{luc}$, respectively, and then treated with GA-A, GA-F and GA-H. As expected, GA-A and GA-H significantly inhibited constitutive activation of AP-1 and $\mathrm{NF}-\kappa \mathrm{B}$, whereas GA-F had no effect on constitutively active AP-1 and NF- $\kappa$ B in MDA-MB-231 cells (Fig. 5). Although our gel shift analysis demonstrated constitutive DNA-binding activity of AP-1 and NF- $\mathrm{KB}$, the DNA binding of AP-1 and NF- $\kappa \mathrm{B}$ was not affected by GA-A, GA-F and GA-H (data not shown). These data confirm that GA-A and GA-H suppress constitutive activation of $\mathrm{AP}-1$ and $\mathrm{NF}-\kappa \mathrm{B}$ at the transactivation level, without affecting their DNA binding.

Effect of GA-A, GA-F and GA-H on the secretion of $U P A$ and UPAR expression in MDA-MB-231 cells. The expression of uPA and UPAR are controlled by AP-1 and NF-кB (14). Therefore, we evaluated whether the inhibition of AP-1 and $\mathrm{NF}-\kappa \mathrm{B}$ by ganoderic acids results in the suppression of uPA secretion and UPAR expression. MDA-MB-231 cells were treated with GA-A, GA-F and GA-H for $24 \mathrm{~h}$, and the expression of UPA was evaluated in cell-conditioned medium by Western blot analysis. The effects of GA-A, GA-F and GA-H on uPAR expression of MDA-MB-231 cells were examined by immunocytochemical staining. Our results showed that GA-A and GA-H markedly reduced the secretion of UPA from MDA-MB-231 cells. As expected, GA-F did not change the secretion of uPA in MDA-MB-231 cells (Fig. 6). Interestingly, GA-A, GA-F and GA-H did not cause any significant change in UPAR expression of MDAMB-231 cells (Fig. 7). These results suggest that the inhibitory 
A

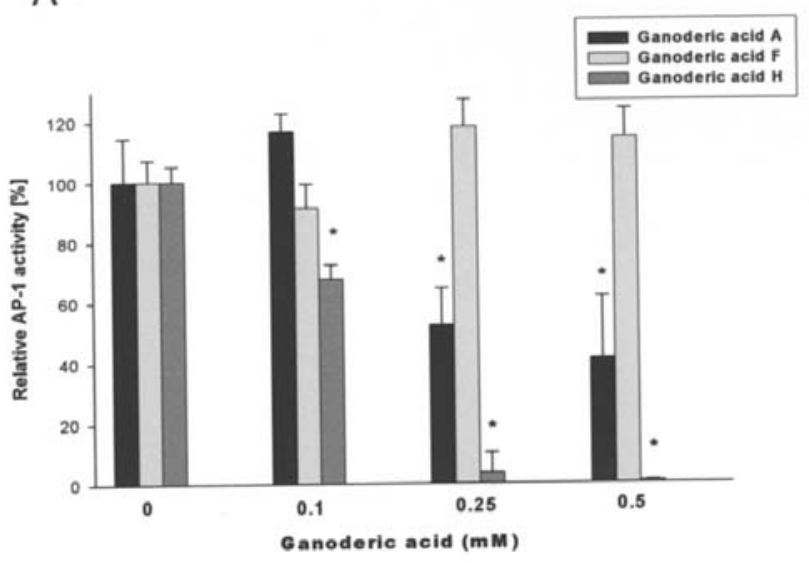

B

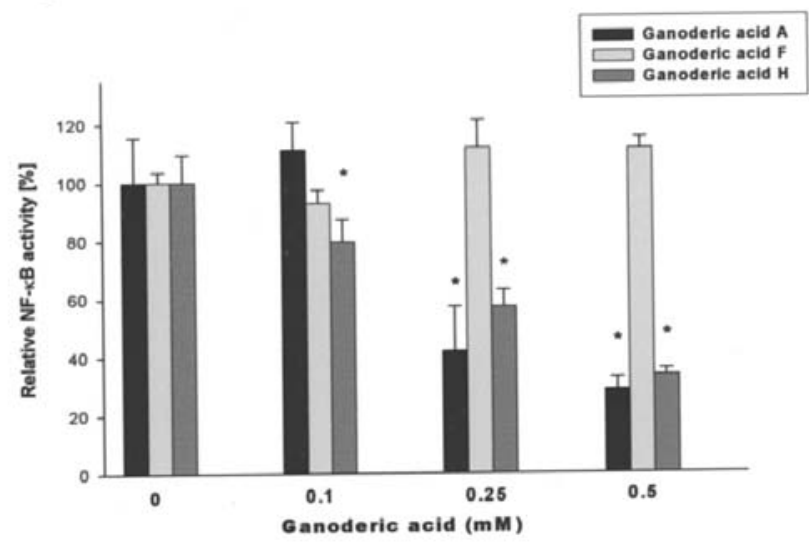

Figure 5. Effect of ganoderic acids on the activity of AP-1 and NF-кB in MDA-MB-231 cells. MDA-MB-231 cells were transfected with $1 \mu \mathrm{g}$ AP-1Luc (A), $1 \mu \mathrm{g} \mathrm{NF- \kappa B-Luc} \mathrm{(B)} \mathrm{reporter} \mathrm{gene} \mathrm{constructs} \mathrm{and} 1 \mu \mathrm{g}$ B-galactosidase expression vector $\mathrm{pCH} 110$. Twenty-four hours after transfection, the cells were treated with GA-A $(0-0.5 \mathrm{mM})$, GA-F $(0-0.5 \mathrm{mM})$ and GA-H $(0-$ $0.5 \mathrm{mM}$ ) for $24 \mathrm{~h}$. AP-1 and NF- $\mathrm{BB}$ activity was determined by luciferase assays as described in Materials and methods. The results are expressed as the percentage of relative AP-1 or NF-кB activity. Each bar represents the mean \pm SD of three experiments; ${ }^{*} \mathrm{p}<0.05$

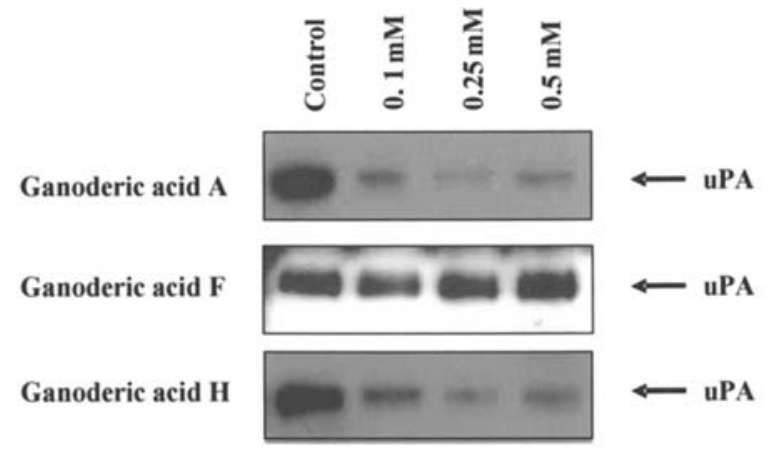

Figure 6. Effect of ganoderic acids on uPA secretion from MDA-MB-231 cells. MDA-MB-231 cells were treated with GA-A (0-0.5 mM), GA-F (0$0.5 \mathrm{mM})$ and GA-H $(0-0.5 \mathrm{mM})$ for $24 \mathrm{~h}$, and the expression of uPA was detected in conditioned media with anti-uPA antibody by Western blot analysis.

effects of GA-A and GA-H on the invasiveness of MDAMB-231 cells can be associated with the down-regulation of uPA secretion, but not altered uPAR expression.

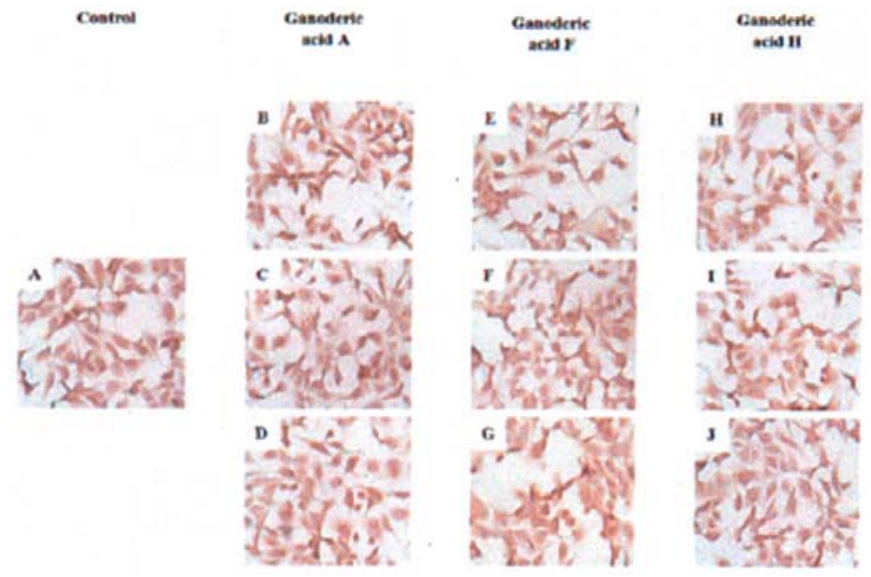

Figure 7. Effect of ganoderic acids on uPAR expression of MDA-MB-231 cells. MDA-MB-231 cells were cultured in multichamber slides and treated with GA-A (0-0.50 mM), GA-F (0-0.50 mM) and GA-H (0-0.50 mM) for $24 \mathrm{~h}$. After $24 \mathrm{~h}$, cells were fixed and then processed for uPAR expression by immunocytochemical staining as described in Materials and methods. (A) control; GA-A: (B) $0.1 \mathrm{mM}$, (C) $0.25 \mathrm{mM}$, (D) $0.5 \mathrm{mM}$; GA-F: (E) $0.1 \mathrm{mM}$, (F) $0.25 \mathrm{mM}$, (G) $0.5 \mathrm{mM}$; and GA-H: (H) $0.1 \mathrm{mM}$, (I) $0.25 \mathrm{mM}$, (J) $0.5 \mathrm{mM}$.

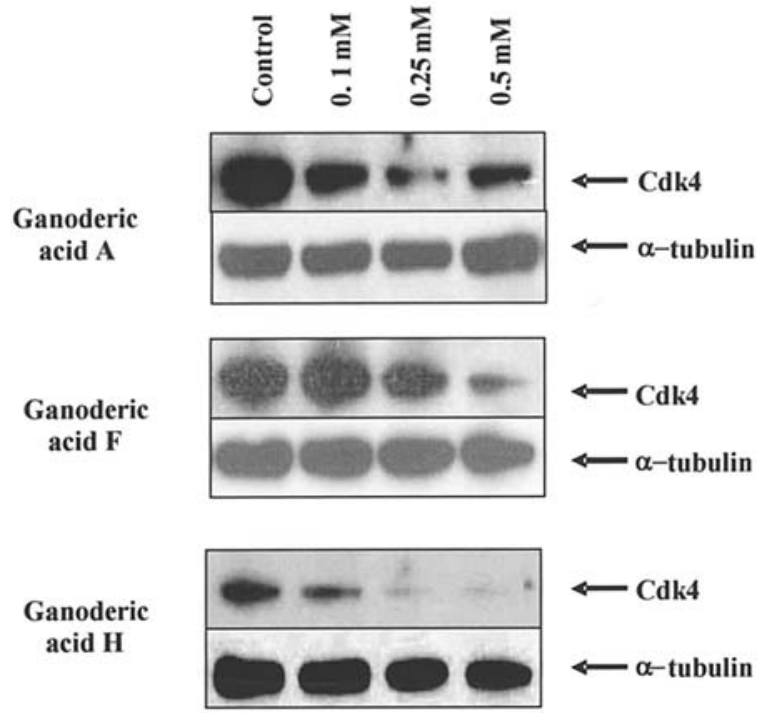

Figure 8. Effect of ganoderic acids on expression of Cdk4 protein in MDAMB-231 cells. MDA-MB-231 cells were treated with GA-A (0-0.5 mM), GA-F (0-0.5 mM) and GA-H (0-0.5 mM) for $24 \mathrm{~h}$, and whole cell extracts were subjected to Western blot analysis. The expression of Cdk4 and $\alpha$-tubulin was evaluated by Western blot analysis with anti-Cdk4 and anti- $\alpha$-tubulin antibodies. Equal protein loading was verified with anti- $\alpha$-tubulin antibody as described in Materials and methods. The results are representative of three separate experiments.

Effect of GA-A, GA-F and GA-H on the expression of Cdk4 in MDA-MB-231 cells. The dysregulation of cell cycle control is another characteristic of cancer (27), and we previously showed that $G$. lucidum arrested the cell cycle in MDA-MB231 cells at $\mathrm{G}_{0} / \mathrm{G}_{1}$ by the down-regulation of cyclin $\mathrm{D} 1$ and Cdk4 kinase (21). Therefore, we hypothesized that GA-A and GA-H would decrease the proliferation of MDA-MB-231 cells by a similar mechanism. The extracts from MDA-MB-231 cells treated with GA-A, GA-F and GA-H were subjected to 
Western blot analysis with Cdk4. As shown in Fig. 8, GA-A and GA-H markedly decreased the expression of $\mathrm{Cdk} 4$ in MDA-MB-231 cells in a dose-response manner. As expected, GA-F did not reduce the expression of Cdk4 in these cells. Collectively, our results suggest that the inhibitory effects of GA-A and GA-H on the growth of MDA-MB-231 cells might be caused by the down-regulation of $\mathrm{Cdk} 4$ expression.

\section{Discussion}

We previously showed that extract from G. lucidum (containing polysaccharides and triterpenes) suppresses cell growth, cell adhesion, migration and invasion in invasive breast cancer cells $(21,26)$. This extract contains GA-A, GA-F and GA-H (15). However, the effect of isolated GA-A, GA-F and GA-H on the growth and invasive behavior of breast cancer cells was not previously addressed. In the present study we showed that GA-A and GA-H inhibited growth and invasive behavior of breast cancer cells, whereas structurally related GA-F was ineffective. The anti-proliferate effect was mediated through the down-regulation of expression of $\mathrm{Cdk} 4$, leading to the inhibition of the cyclin D1/Cdk4 complex. This observation is in agreement with our previous study demonstrating cell cycle arrest at the $\mathrm{G}_{1} / \mathrm{G}_{0}$ phase of breast cancer cells and the downregulation of Cdk4 by G. lucidum (21). Recently, Tang et al (20) showed that another triterpenoid purified from G. lucidum mycelia, ganoderic acid $\mathrm{T}$, arrests lung cancer cells at the $\mathrm{G}_{1} / \mathrm{G}_{0}$ phase.

GA-A and GA-H also inhibited adhesion, migration and invasion with the down-regulation of uPA secretion in MDAMB-231 cells. These data suggest that GA-A and GA-H inhibit the invasive behaviors of breast cancer cells by modulating the secretion of uPA. As shown above, GA-A and GA-H inhibit AP-1 and NF- $\mathrm{B}$ activity in highly invasive human breast cancer cells. Since AP-1 and NF- $\mathrm{KB}$ binding sites exist at the promoter region of UPA (28), the suppression of secretion of UPA by GA-A and GA-H might be mediated by the inhibition of transactivation of AP-1 and NF- $\kappa$ B. Nevertheless, it is possible that the inhibition of $\mathrm{UPA}$ secretion by GA-A and GA-H could be mediated by other mechanisms including posttranscriptional regulation of uPA mRNA (29). We previously showed that expression of UPAR is controlled by NF-кB and AP-1, and the extract of G. lucidum downregulates expression of UPAR in MDA-MB-231 as well as in PC-3 cells $(13,14)$. However, in the current study we were not able to demonstrate the inhibitory effect of GA-A and GA-H on the expression of uPAR. Because the extract of G. lucidum used in our previous study contained both polysaccharides and triterpenes, it is possible that polysaccharide fractions, or their combination with triterpenes, were able to down-regulate uPAR expression.

As we clearly demonstrated, the triterpene structure of ganoderic acids plays a crucial role in their biological activity. Our data suggest that the activity of ganoderic acids could be especially linked to the hydroxylation of their lanostane triterpene structure. The active GA-H is hydroxylated at position 3 and GA-A at position 7 and 15; whereas inactive GA-F is not hydroxylated. In addition, other triterpenes with hydroxyl or acetoxy groups at the positions 3, 7 and/or 15 such as ganoderic acid C1, ganoderic acid C2 (30), ganoderic acid D (31), ganoderic acid T (20), ganoderic acid X (19), ganoderic acid Y (32), ganoderiol A (31), ganoderol B $(32,33)$, lucidumol B and ganodermadiol $(30,31)$ were shown to have inhibitory biological activity. Shiao (34) demonstrated that several Ganoderma triterpenes with hydroxyl or acetoxy groups in these positions were cytotoxic to hepatoma cells and inhibited histamine release, cholesterol synthesis, and farnesylation of Ras protein. Hajjaj et al (32) showed that ganoderic acid $\mathrm{Y}$ and ganoderol $\mathrm{B}$ inhibited cholesterol synthesis in human hepatic T9A4 cells. Li et al (19) reported that ganoderic acid X induced immediate inhibition of DNA synthesis and cell apoptosis in human hepatoma HuH-7 cells. Tang et al (20) demonstrated that ganoderic acid $\mathrm{T}$ induced apoptosis of metastatic lung tumor cells. Liu et al (31) also reported that ganoderic acid D, ganoderiol A, lucidumol B and ganodermadiol inhibited $5 \alpha$-reductase activity of rat microsomes. Akihisa et al (30) also showed that ganoderic acid $\mathrm{C} 1$ and ganoderic acid $\mathrm{C} 2$ have inhibitory effects on the induction of Epstein-Barr Virus early antigen. Liu et al (33) recently showed that ganoderol $\mathrm{B}$ has the ability to bind to the androgen receptor, inhibit androgen-induced growth of prostate cancer cells and suppress re-growth of the ventral prostate induced by testosterone in rats.

In conclusion, in this study we demonstrated a possible mechanism by which GA-A and GA-H isolated from G. lucidum inhibit the growth and invasive behaviors of human breast cancer cells. The anti-invasive effects of GA-A and GA-H on MDA-MB-231 cells may be mediated through the inhibition of AP-1/NF-кB-dependent secretion of uPA, while the antiproliferate effects of GA-A and GA-H on MDA-MB-231 cells may be mediated through the down-regulation of expression of Cdk4. Although our data suggest that the hydroxylation at positions 3, 7 and/or 15 in the lanostane triterpene structure is crucial for the biological activity of ganoderic acids, our study is limited only to the three triterpenes isolated from G. lucidum. Further studies are in progress to determine the relationship between the structure and biological activity of mushroom triterpenes for the development of novel agents for the treatment of breast cancer.

\section{Acknowledgements}

This work was supported by the Methodist Health Foundation and by the Department of the Army Medical Research and Material Command, Breast Cancer Research Training Program.

\section{References}

1. Jemal A, Siegel R, Ward E, Murray T, Xu J and Thun MJ: Cancer statistics, 2007. CA Cancer J Clin 57: 43-66, 2007.

2. Pasqualini JR: The selective estrogen enzyme modulators in breast cancer: a review. Biochim Biophys Acta 1654: 123-143, 2004.

3. Price JT and Thompson EW: Mechanisms of tumour invasion and metastasis: emerging targets for therapy. Expert Opin Ther Targets 6: 217-233, 2002.

4. Jemal A, Siegel R, Ward E, Murray T, Xu J, Smigal C and Thun MJ: Cancer statistics, 2006. CA Cancer J Clin 56: 106-130, 2006.

5. Sliva D: Signaling pathways responsible for cancer cell invasion as targets for cancer therapy. Curr Cancer Drug Targets 4: 327-336, 2004. 
6. Allgayer $\mathrm{H}$ : Molecular regulation of an invasion-related molecule - options for tumour staging and clinical strategies. Eur J Cancer 42: 811-819, 2006.

7. Kundu JK and Surh YJ: Molecular basis of chemoprevention by resveratrol: NF-kappaB and AP-1 as potential targets. Mutat Res 555: 65-80, 2004.

8. Eferl R and Wagner EF: AP-1: a double-edged sword in tumorigenesis. Nat Rev Cancer 3: 859-868, 2003.

9. Milde-Langosch $\mathrm{K}$ : The Fos family of transcription factors and their role in tumourigenesis. Eur J Cancer 41: 2449-2461, 2005.

10. Lu H, Li J, Zhang D, Stoner GD and Huang C: Molecular mechanisms involved in chemoprevention of black raspberry extracts: from transcription factors to their target genes. Nutr Cancer 54: 69-78, 2006.

11. Sovak MA, Bellas RE, Kim DW, Zanieski GJ, Rogers AE, Traish AM and Sonenshein GE: Aberrant nuclear factor$\mathrm{kappaB} / \mathrm{Rel}$ expression and the pathogenesis of breast cancer. J Clin Invest 100: 2952-2960, 1997.

12. Daschner PJ, Ciolino HP, Plouzek CA and Yeh GC: Increased AP-1 activity in drug resistant human breast cancer MCF-7 cells. Breast Cancer Res Treat 53: 229-240, 1999.

13. Sliva D, Labarrere C, Slivova V, Sedlak M, Lloyd FP Jr and Ho NW: Ganoderma lucidum suppresses motility of highly invasive breast and prostate cancer cells. Biochem Biophy Res Commun 298: 603-612, 2002.

14. Sliva D, English D, Lyons D and Lloyd FP Jr: Protein kinase C induces motility of breast cancers by upregulating secretion of urokinase-type plasminogen activator through activation of AP-1 and NF-kappaB. Biochem Biophys Res Commun 290: 552-557, 2002.

15. Thyagarajan A, Jiang J, Hopf A, Adamec J and Sliva D: Inhibition of oxidative stress-induced invasiveness of cancer cells by Ganoderma lucidum is mediated through the suppression of interleukin-8 secretion. Int J Mol Med 18: 657-664, 2006.

16. Sliva D: Cellular and physiological effects of Ganoderma lucidum (Reishi). Mini Rev Med Chem 4: 873-879, 2004.

17. Gao JJ, Min BS, Ahn EM, Nakamura N, Lee HK and Hattori M: New triterpene aldehydes, lucialdehydes A-C, from Ganoderma lucidum and their cytotoxicity against murine and human tumor cells. Chem Pharm Bull 50: 837-840, 2002.

18. Gao Y and Zhou S: Cancer prevention and treatment by Ganoderma, a mushroom with medicinal properties. Food Rev Int 19: 275-325, 2003.

19. Li CH, Chen PY, Chang UM, Kan LS, Fang WH, Tsai KS and Lin SB: Ganoderic acid X, a lanostanoid triterpene, inhibits topoisomerases and induces apoptosis of cancer cells. Life Sci 77: 252-265, 2005

20. Tang W, Liu JW, Zhao WM, Wei DZ and Zhong JJ: Ganoderic acid T from Ganoderma lucidum mycelia induces mitochondria mediated apoptosis in lung cancer cells. Life Sci 80: 205-211, 2006.
21. Jiang J, Slivova V, Harvey K, Valachovicova T and Sliva D: Ganoderma lucidum suppresses growth of breast cancer cells through the inhibition of Akt/NF-kappaB signaling. Nutr Cancer 49: 209-216, 2004.

22. Lloyd FP Jr, Slivova V, Valachovicova T and Sliva D: Aspirin inhibits highly invasive prostate cancer cells. Int J Oncol 23: 1277-1283, 2003

23. Jiang J, Chang HL, Sugimoto Y and Lin YC: Effects of age on growth and ERbeta mRNA expression of canine prostatic cells. Anticancer Res 25: 4081-4090, 2005.

24. Jiang J, Slivova V and Sliva D: Ganoderma lucidum inhibits proliferation of human breast cancer cells by down-regulation of estrogen receptor and $\mathrm{NF}-\kappa \mathrm{B}$ signaling. Int J Oncol 29: 695-703, 2006.

25. Wang LH: Molecular signaling regulating anchorageindependent growth of cancer cells. Mt Sinai J Med 71: 361-367, 2004.

26. Slivova V, Valachovicova T, Jiang J and Sliva D: Ganoderma lucidum inhibits invasiveness of breast cancer cells. J Cancer Integr Med 2: 25-30, 2004.

27. Elsayed YA and Sausville EA: Selected novel anticancer treatments targeting cell signaling proteins. Oncologist 6: 517-537, 2001.

28. Crippa MP: Urokinase-type plasminogen activator. Int J Biochem Cell Biol 39: 690-694, 2007.

29. Shetty S: Protein synthesis and urokinase mRNA metabolism. Mol Cell Biochem 271: 13-22, 2005.

30. Akihisa T, Nakamura Y, Tagata M, Tokuda H, Yasukawa K, Uchiyama E, Suzuki T and Kimura Y: Anti-inflammatory and anti-tumor-promoting effects of triterpene acids and sterols from the fungus Ganoderma lucidum. Chem Biodivers 4: 224-231, 2007.

31. Liu J, Kurashiki K, Shimizu K and Kondo R: 5alpha-reductase inhibitory effect of triterpenoids isolated from Ganoderma lucidum. Biol Pharm Bull 29: 392-395, 2006.

32. Hajjaj H, Mace C, Roberts M, Niederberger $P$ and Fay LB: Effect of 26-oxygenosterols from Ganoderma lucidum and their activity as cholesterol synthesis inhibitors. Appl Environ Microbiol 71: 3653-3658, 2005.

33. Liu J, Shimizu K, Konishi F, Kumamoto S and Kondo R: The anti-androgen effect of ganoderol $\mathrm{B}$ isolated from the fruiting body of Ganoderma lucidum. Bioorg Med Chem 15: 4966-4972, 2007.

34. Shiao MS: Natural products of the medicinal fungus Ganoderma lucidum: occurrence, biological activities, and pharmacological functions. Chem Rec 3: 172-180, 2003. 